\title{
Embodied Information Practices
}

Michael Olsson, University of Technology, Sydney

Annemaree Lloyd, Charles Sturt University

The concept of embodied information practices and its implications for information research and professional practice are examined. The presentation draws on the researchers' empirical research in a range of different contexts (firefighting, nursing, chronic illness, theatre production and archaeology) to provide insights into the experiential, affective and embodied elements of information practices.

, Research into the relationship between people and information has been dominated by an 'information behaviour' discourse (Savolainen, 2007), which constructs user behaviour as an essentially problem-focussed, individual, purposive and cognitive process. More recently "a more sociologically and contextually oriented line of research" (Talja, 2005) has emerged which "shifts the focus away from the behavior, action, motives and skills of monological individuals..." (Savolainen $2007,120)$ As an alternative perspective this 'information practices' discourse acknowledges how people engage with existing discourses and social practices. However, whilst studies drawing on this have played a valuable role in highlighting the importance of language for information practices, studies considering non-linguistic embodied practices remain relatively rare in our field. ( Lloyd 2010).

In this presentation, we extend the information practices viewpoint by connecting it to understandings drawn from a range of different approaches, including practice theory and SenseMaking. Drawing on the findings of our empirical studies into firefighters, renal nurses, patients with chronic illness, theatre professionals and archaeologists, we explore the dynamic, embodied and physical sense making processes involved in information practices. In so doing, we create necessary connections between three key elements of embodied information practices: the social mediation involved in information practices; the iterative feedback loops involved in enactive sense making, and practice theoretic perspectives on the body and enactment.

\section{References}

Lloyd, A. (2010). Framing information literacy as information practice: Site ontology and practice theory. Journal of Documentation, 66(2), 245-268.

Savolainen, R. (2007). Information behavior and information practice: Reviewing the "umbrella concepts" of information-seeking studies. The Library Quarterly, 77(2), 109-132.

Talja, S. (2005). The domain analytic approach to scholar's information practices. In K. Fisher, S. Erdelez, and L. McKechnie (Eds.), Theories of information behavior. (pp. 123-27). Medford, NJ: Information Today. 